Revue d'histoire de l'Amérique française

Q REVUE D.HISTOIRE DE L'AMÉRIQUE FRANÇAISE

\title{
STRONG-BOAG, Veronica et Anita Clair FELLMAN, dir., Rethinking Canada. The Promise of Women's History. Toronto, Copp Clark Pitman, 2e éd., 1991. 454 p. 19,95 \$.
}

\section{Lucia Ferretti}

Volume 45, numéro 3, hiver 1992

URI : https://id.erudit.org/iderudit/305012ar

DOI : https://doi.org/10.7202/305012ar

Aller au sommaire du numéro

Éditeur(s)

Institut d'histoire de l'Amérique française

ISSN

0035-2357 (imprimé)

1492-1383 (numérique)

Découvrir la revue

Citer ce compte rendu

Ferretti, L. (1992). Compte rendu de [STRONG-BOAG, Veronica et Anita Clair FELLMAN, dir., Rethinking Canada. The Promise of Women's History. Toronto, Copp Clark Pitman, 2e éd., 1991. 454 p. 19,95 \$.] Revue d'histoire de l'Amérique française, 45(3), 472-472. https://doi.org/10.7202/305012ar d'utilisation que vous pouvez consulter en ligne.

https://apropos.erudit.org/fr/usagers/politique-dutilisation/ 
STRONG-BOAG, Veronica et Anita Clair FELLMAN, dir., Rethinking Canada. The Promise of Women's History. Toronto, Copp Clark Pitman, $2^{e}$ éd., 1991. 454 p. 19,95\$

C'est un livre assez différent de celui paru en 1986 qui est publié en seconde édition. En effet, des vingt-quatre contributions du recueil, quinze ne figuraient pas la première fois et quatorze ont été écrites ces cinq dernières années. Les objectifs sont par contre restés les mêmes: offrir un panorama aussi vaste que possible de l'expérience des femmes au Canada des origines à nos jours et de Terre-Neuve à la Colombie-Britannique, et tenter par là de forcer ce que les éditrices considèrent un peu comme l'histoire officielle à intégrer davantage les réalités et les points de vue des femmes dans la construction du savoir historique.

Conformément aux axes de recherche développés depuis une dizaine d'années en histoire des femmes, chercheures chevronnées et jeunes disciples nous offrent donc, en un large éventail, des articles sur la maternité et la famille, l'éducation des filles, le travail des femmes et la lutte pour l'accès aux professions, et la participation des femmes à la vie politique. Soulignons une des forces du recueil, rare dans ce type d'ouvrages: les Amérindiennes et les Canadiennes françaises du Québec n'ont pas été oubliées. Au total, un bon moyen de prendre le pouls de l'historiographie contemporaine dans le domaine. 